\title{
18 Relating Differently: Exploring How a Relational Ontology Might Catalyze Transformative and Emancipatory Action- Oriented MSR Research
}

\begin{abstract}
The purpose of this chapter is to explore how enacting a relational ontology as a researcher might restore/repair the deep interconnection and interdependence between all life on the planet. While ontological matters might be considered too philosophical or far removed from the practical matters of research, this chapter seeks to illuminate the importance of adopting a relational ontological perspective, with the intention to continue to enhance the future-forming capacity of Management, Spirituality and Religion (MSR) researchers.

The term 'relational ontology' is used to describe various philosophies or ways of knowing that blur the distinction between subject and object; between researcher and the researched; and between human and nature. These philosophies/ways of knowing offer diverse ways to critically reflect on researcher subjectivity, competencies, and skills needed for meaningful MSR research. The preparation or development of the researcher and the practical research design decisions and actions are impacted by these ontologies, with significant consequences to the purpose, implementation, and potential impact of the studies. This chapter seeks to offer MSR researchers new ways to design and conduct transformative and emancipatory action-oriented research in this critical historical moment of tumultuous change and chaos.
\end{abstract}

\section{Why Relational Ontologies?}

This chapter is about what is real (ontology) and the implications of what is real for Management, Spirituality, and Religion (MSR) research. Quantum reality, as I understand and experience it, was best described by David Bohm (1980) as an unfolding co-emergence of energy into matter. The phrase relational ontology signifies this deep interdependence and co-creation of reality. Over time, I have learned that this way of understanding the world has been described in multiple and diverse ways for example, actor network theory (Latour, 2005), agential realism (Barad, 2003), revolutionary critical pedagogy (Allman, 2001); autopoiesis (Maturana \& Varela, 1980), relational being (Gergen, 2009), posthumanism (Braidotti, 2018), a quantum worldview (Tsao \& Laszlo, 2019), and the implicit order in quantum theory (Bohm, 1980). 
From these relational positions, a researcher's ideas and actions emerge within/ from contexts, and context itself is a 'player' in the game of conducting research as much as the brain, intellect, cognition, and decision making. This stance is far from Newtonian separation and the paradigm of scientific reduction and cause-effect thinking. MSR scholarship has had to contend with this paradigm since its inception the science of reduction to discover natural laws and generalizable results has been the gold standard for organizational and management scholars and researchers. MSR researchers have struggled to legitimize subjective ways of knowing and conducting research (Lin et al., 2016); they have had to find objective measures (MacDonald, 2011); and have been advised to operationalize and define terms (Tackney, Chappell, Harris, Pavlovich, Egel, Major, Finney, \& Stoner (2017) in order to legitimize MSR research.

This chapter seeks to build on/from this scholarship to envision a new way of being a MSR researcher. This requires a shift in consciousness - from a consciousness of separation (e.g., typical for organization and management science research) - to a new way of being in the world that recognizes the interdependence and dependent origination (a Buddhist principle recognizing the mutuality of causation) of all of the material world. Rather than premised on separateness, this chapter suggests the future of MSR research should instead get closer. As described by Cuomo,

... knowledge producers who aim to get closer abandon the dream of scientific progress which seeks absolute knowledge in the service of enlightened mastery and wealth, working instead for knowledge that acquaints us with the particulars of the world we affect. Arrogant inquiries accept a comfortable distance between knowledge and life, and hide their limits and inadequacies behind an epistemic (knowledge-making) posture that proclaims a unified route to knowing, a route that necessarily follows traditions of privilege and exclusion.

(Cuomo, 2020, pp. 66-67; italics mine)

Getting closer is a metaphor, a pointer to what I argue is a relational approach to MSR research that is transformative, educative, and emancipatory. In this relational ontology, research has the potential to transform the researcher as much as the researched, because getting closer generates a moral obligation for care and a form of sacred reciprocity akin to Indigenous research methods (Kimmerer, 2013; Wilson, 2008). Modern science (starting with Galileo Galilei) does not get closer in a moral sense; indeed, as argued by Loizzo (2020), modern science has "undermined our faith in humanity and in the perfectibility of human society" and has fostered a "modern skepticism about our human potential for personal and social integration,” (p. 72). Getting closer is a departure from the science of separation, objectification, and reduction, and it offers a compelling, relational route forward for impactful MSR research.

I believe relational ontologies and the intent to get closer are also a resistance to the assumptions and values associated with normal science. Getting closer is not widely recognized in the neo-liberal academy as a valid form of knowledge production, where competition, separation, rationality, and hierarchy are valued. Even the idea of production of knowledge itself would be resisted from a relational perspective, 
with the argument that the researcher is embedded within the production process and therefore a part of the results or findings. In the neo-liberalism of the academy, however, knowledge can be produced, consumed, and commodified. Because of these norms and values, researchers and educators teaching about relational ontologies and conducting research from this position often turn to non-Euro Western ideas, books, and articles for information and inspiration.

Likewise, over the years of teaching and research, I have found myself including more and more non-Euro-Western perspectives into my research projects and research design classes; the most recent addition has been to take a deep dive into relational ontologies - the focus of this chapter. For example, in a recent research design class one of the textbooks selected was authored by a feminist philosopher (Thayer-Bacon, 2017), and guest speakers and other assigned readings were from Indigenous scholars - as well as from diverse ethico-onto-epistemological perspectives. These readings and guest scholars, while positioned differently, all pointed to the critical idea of connection; of relation; of some sort of ethical responsibility grounded in reciprocity. They all pointed to the 'fact' that humans are part of nature; not objective observers of nature who stand apart from it.

On reflection, I now understand that by incorporating relational ontologies into the doctoral classroom was a strategy of resistance to the traditional view of a mechanized universe with separate cause and effect relationships - the paradigm that feminists suggest is a result of patriarchal ways of knowing and studying the world. At the same time, I continue to learn that both/and, yin/yang, and neither/ nor might be a better way to understand how best to teach scholarly inquiry and do my own research. Most importantly, I believe that if one enacts a relational ontological perspective, they are given a powerful vantage point from within to design and execute any type of research design - be it quantitative or qualitative or mixed methods - that seeks to get closer. A relational ontological perspective dissolves the separation between researcher and researched, and instead invites the radical perspective of being infused by and emmeshed within an all-encompassing field of information and energy. Humans are in nature; of nature; not separate from it. Researchers are infused by and in relationship with the researched. This perspective, in my opinion, provides MSR researchers - because they are concerned with the spiritual, the sacred, and the meaningful - with the potential to conduct transformative, catalytic research for change.

\section{So What Exactly Are Relational Ontologies?}

I offer three different ways to begin to make sense of relational ontologies. First, I agree with noted educational scholar and feminist Barbara Thayer-Bacon's view that 'ontology' and 'spirituality' might be used interchangeably because both "help hold our 
worlds together and give meaning to our lives” (2017, p. 3). In this view, relational ontologies are nondualistic ways of understanding the world that "emphasize we are w/ holistically connected with our greater universe, materially and spiritually," (2017, p. 7). Thayer-Bacon offers the analogy of an ocean, a boat, and a fishing net to describe her idea of a relational ontology. In this view, all of the cosmos is represented as the vast ocean, representing all pure experience. We can't possibly know all of this vastness, so we create a net to help us make sense of it. Thayer-Bacon (2017) suggests:

what we use to make these nets are our theories of knowing (epistemology) as well as our the-
ories of being (our ontology). There are multiple kinds of epistemological and ontological nets
we can design, maybe even an infinite variety, some more effective than others, in terms of the
amount of Ocean life they are able to catch up... Whatever epistemological and ontological
net we use, however fine the weaving, there is so much more in this vast Ocean of experience
that our nets can catch. When we cast our nets, much will overflow the top of our nets as well
as spill through it and escape back into the infinite Ocean. We cannot divorce ourselves from
epistemological and ontological questions for they form the very weaving of the nets we use to
catch up our everyday concerns and give them meaning.

In this metaphor, the net consists of warp and weft threads; the warp represents our ontological theories (e.g., being, or what is), and the weft our epistemological theories (e.g., how we know). While both threads of the weave are important, the weft thread generates the essence of our human experience. Thayer-Bacon suggests that ontology and spirituality are synonyms because the first being is "not tangible or material, and is primal to our survival" (2017, p. 3), and so the weft threads of the net substantially shape the meaning we give to our human experience. ThayerBacon goes on to describe how humans make their nets - first from inheriting the net from parents and family, then in school revising/repairing the net as learning and independence develop, then in adulthood through relationships. Our nets are not made in isolation, they are constantly created and re-created through experience and relationships, and unless the nets are made visible to us we run the risk of claiming that our experience is True. Once made visible (e.g., conscious) to us, we are more able to recognize the partiality, the limits to our knowing, and recognize the incredible vastness of All That Is.

This view of a relational ontology has profound implications for research and scholarship because it absolutely denies the existence of a separation between knower (the researcher) and the known (the researched). What we see, understand, and name is a function of our ontological and epistemological perspectives. A scholar/researcher in this view would be humble in all knowledge claims because they would recognize the 'vast Ocean of experience' that their research design did not catch up.

The second relational ontology I want to describe is from quantum theory. From this perspective, empirical scientific results combine with mathematical modeling to suggest the existence of what David Bohm calls an implicate order of energy and information. In this view, the implicate order is the basis of the universe; consciousness 
and matter co-emerge; and importantly for researchers - the implication is that there is no separation between researcher, the researched, and research instruments. Many scholars and philosophers have offered profound ideas about this interconnection, or 'consciousness of connectedness' (Tsao \& Laszlo, 2019), and why it matters. For example, feminist/physicist/philosopher Karen Barad (2003) offers a perspective based on quantum theory called agential realism, which describes a reality in which every 'thing' is connected in a web of relations. In the agential realist view, a human has no more agency (think 'influence') over a collective experience (think workplace learning, or meaningful work) than do ideas, policies, culture/norms, technology, organizational structure, and so on. Agential realism, as I understand it, points to the co-creation of experience/meaning among human and non-human 'agents' and requires researchers to re-position themselves and their views of what is real. In agential realism, as with quantum theory, all material matter (e.g., what we see; what David Bohm calls the explicate order) co-emerges relationally. In this view, one cannot disconnect human experiencing from context; from practices; or from structure. This is a deep form of relational ontology - what is, comes into being through relations.

The third form of relational ontology I present in this chapter is from the Indigenous perspective. In describing Indigenous ideas, it is critically important to recognize how both individual and structural positions of power and advantage contribute to my research and scholarship (D'Arcangelis, 2018). As a White settler writing this chapter from my office on Massawomek and Manahoac land, I recognize the potential for me to further colonize the Natives of Turtle Island (North America) by appropriating Indigenous ontology, epistemology, and axiology. (Note: from what I understand, it is not possible to separate out reality (ontology) from knowing (epistemology) from responsibility (axiology) in Indigenous ways of knowing (IWOK). The separation of these concepts are offered here because that is how Western minds have been trained and developed - mine included).

As a White settler, I step into an impossible, liminal space when writing about, using, and describing Indigenous philosophies. Critical reflection about these matters is not sufficient, because it still assumes there is an "I" separate from others and separate from the structures of oppression within which I live and work. D'Arcangelis (2018) builds on Ahmed's (2004) reflexive double turn to propose a radical reflexivity, itself "a form of critical analysis, which would examine our subjectivities as windows into the operation and potential alteration of social structures in which we are fully implicated," (p. 12; italics mine). Radical reflexivity about Indigenous ideas is itself a characteristic of a relational ontology - a knowing that I as a researcher co-create the structures of oppression and privilege of ideas and research values that permeate the academy. In this view, I am fully implicated in the perpetuation of hierarchies of power and privilege - of knowledge, ideas, and research practices considered 'better' than others.

And, at the same time, I can honor and respect IWOK, philosophies, and research design practices. I have personally been told by multiple Indigenous scholars that 
with honor and respect and attribution, I can serve the sacred through teaching, research, and practices infused with IWOK. Consequently, I offer what I am learning in the classroom, through my research, and in my activism.

The next section are ideas drawn from Sean Wilson's Research is Ceremony: Indigenous Research Methods (2008); Robin Wall Kimmerer's (2013) Braiding Sweetgrass: Indigenous Wisdom, Scientific Knowledge, and the Teaching of Plants; and from Lyla June Johnston's Master's Thesis Diné Bina'nitin Dóó O’hoo'aah/Education For Us, By Us: A Collective Journey in Diné Education Liberation. These selections represent a diverse array of ideas and research practices that are grounded in an ethic of the inherent sovereignty and mindedness of all matter - human, animal, plant, cosmos; as well as responsibility, relations, and reciprocity. Human and nonhuman beings are integrally related in this relational ontology, and the dignity of all beings is a key principle. At once this ontological position places humans with nature, inseparable from it, and ethically and morally obligated to protect it, to ensure flourishing, and to work to correct/repair anything that diminishes dignity.

The three relational ontologies presented here - Thayer-Bacon's spirituality/ontology that gives integral meaning to existence; quantum theory findings suggesting energetic, co-emergent connection between all we see and do; and Indigenous ontologies demanding respect and reciprocity - all three shift the researcher/researched relationship in subtly different ways, and all three offer MSR researchers with a new grounding to conduct transformative and impactful research.

The next section presents research ideas from the three Indigenous scholars listed above to illuminate how profoundly coherent they are with the contemporary issues facing MSR and the world. It is as if the unfolding of human experience with the planet and all of its inhabitants has co-generated this light in our time of darkness; the light, to me, is the Indigenous way relating to all things as sacred, in a ceremonial sense, through the moral imperative of dignity and respect. Enacting this way of being in the world offers MSR researchers a powerful path towards generating meaningful and transformative research.

\section{Indigenous Ways of Knowing (IWOK) and Research}

I recently had an email exchange with an Indigenous scholar/activist about the difference between the words spirituality and ceremony. I was using the phrase 'Indigenous spirituality' to signify what I understood to be the multiple/diverse ways of being in unity with the sacred in my understanding of IWOK. My friend suggested that the phrase 'Indigenous ceremony' would be a better representation (thank you, Lyla June Johnston). The word shift had an immediate impact on me, and I saw the profound understanding of the sacredness of being human through understanding life itself is ceremony. Euro-western cultural norms have relegated ceremony and ritual far away from the center of what it means to be human. In contrast, traditional 
eastern wisdom has long emphasized the importance of ceremony and ritual (禮/lǐ), for example in Confucius' Analects Book I. And often, the word spirituality suggests a disembodied, 'higher' self that can transcend the material world.

But Indigenous ceremony pulls me back into my body; into my sweating, aching, breathing, stretching, bone and blood and muscle body. This is an experience of the sacred, if I choose to think and know that my embodied life is ceremony. My embodied life is an expression of the Source and of all that is sacred. Extending through to my embodied cognition and embodied mind, my ideas, writings, and research are also ceremony.

I should have known this months ago, through reading Shawn Wilson's book Research is Ceremony: Indigenous Research Methods. Despite the title telling me of the importance of the word ceremony, I didn't get it until my friend catalyzed a new, deeper, and more integrated understanding. I share this learning curve with you to illuminate the continual unfolding, the continual deepening, the continual sublime experiences of coming to know more about the sacred. I can be tuned in doing research, grocery shopping, walking my dog, going to faculty meetings. All can be ceremony if I choose to open to that potential.

Wilson's book is an exemplary contribution for sharing with the world an Indigenous relational ontology. For example, Wilson describes the inseparability of methodology and axiology when conducting research through IWOK:

... we [researchers] are mediators in a growing relationship between the community and whatever it is that is being researched. And how we go about doing our work in that role is where we uphold relational accountability. We are accountable to ourselves, the community, our environment or cosmos as a whole, and also to the topics we are researching. We have all of these relationships that we need to uphold.

(2008, p. 106)

Research as ceremony remains anchored in the body, infused by context completely. And, contextualizing knowledge demands integrity. An embodied, contextual understanding “ . . . is necessary for that knowledge to become lived, become a part of our collective experience or part of our web of relationships," (Wilson, 2008, pp. 102-103). There is responsibility connected to knowledge and knowing that cannot be separated in IWOK; I understand this to be an ethical imperative because the lived knowledge that can be generated from research must enhance the sacredness of all life.

I invite all MSR researchers to consider reading Wilson's text, which offers substantive and powerful ideas for catalyzing the next generation of MSR research and scholarship. Here is one more quote from this powerful book that illuminates the deep adherence to a relational ontology:

. . . if the researcher is separated from the research and it [the research] is taken away from its relationships, it will not be accepted within an Indigenous paradigm. The research will not show respect for the relationship between the research participants and topic . . . the research must accurately reflect and build upon the relationships between the ideas and the participants...

(Wilson, 2008, p. 101) 
Like Wilson (2008), Johnston (2017) and Wall Kimmerer (2013) are deeply grounded in a relational ontology, and each researcher offers examples of empirical research that bridges the material and subtle worlds through IWOK. The research is emancipatory, affirms the moral imperative of dignity of all, and is very embodied. These exemplars offer MSR researchers unique and powerful ways to see and sense how to get closer through IWOK. The invitation is open for readers to access this powerful wisdom.

The next section presents select details about why and how MSR research might be conceptualized and conducted through enacting a relational ontology. It is hoped with these new perspectives, MSR scholars can continue to build on the corpus of knowledge implicitly drawn at the intersection of IWOK, relational, and quantum ontology, and be catalysts for research that is deeply transformative.

\section{Enacting/Generating Research from a Relational Ontology}

This section offers answers to the questions: Why should MSR researchers enact a relational ontology? How might MSR researchers conduct research from this ontological perspective? Both types of questions have been debated by previous scholars, as will be described below, however with a subtle but important difference in focus.

\section{Why Should MSR Researchers Enact a Relational Ontology?}

Many scholars focus on changing a researcher's paradigm by creating arguments to validate subjective knowledge and reduce the distance between researcher and researched. These arguments often revolve around making the case for qualitative research as the 'best' way to understand meaning and spiritual phenomena, and the focus is on changing the paradigm or belief-system of the researcher from 'objective' science to 'subjective' experience.

The argument I am making here is different and perhaps more dis-locating in its impact. My argument does not attempt to legitimize subjective knowledge. My argument is an ontological argument about reality and it is centered on its epistemological correlates based on Indigenous, quantum, and relational ways of being in/with the material and subtle world. It is not about legitimizing qualitative research; in fact, as I mentioned earlier all forms of research (qualitative, quantitative, or mixed-methods) could be conducted from a relational ontological perspective.

Definitions are important, and there is a profound difference between paradigm and ontology. As described by Kuhn (1962), a paradigm represents a 'mature' science when there is consensus on theories, procedures, and models. Conversely, he labeled 
as 'immature' a science (historically, the domain of spirituality) that does not have theoretical or procedural consensus. In both categories of paradigm, the researcher is outside of the research project looking in as an objective, neutral observer. There is a separation between researcher and researched when one is talking about paradigm; this is completely different when one is talking about a relational ontology as I've described it earlier in the chapter.

Enacting a relational ontology involves being different as a researcher, and while some authors (for example Lin et al., 2016) describe practices for developing the 'inner landscape' of the researcher that enables being different, there are profound implications for designing research that remain unnamed in much of this previous work because, I think, the focus was on paradigm rather than ontology. The focus was on the lens or on the metaphor rather than What Is.

One of the seminal research textbooks relevant to this discussion is the book, Toward a Spiritual Research Paradigm: Exploring New Ways of Knowing, Researching, and Being. In this path-breaking work, authors Lin, Oxford, and Culham (2016) make a compelling case for the development of a spiritual research paradigm because "a large and vital part of human experience is excluded from the current research paradigms" (p. x). They also argue that "researchers need to embody what they research. This means researchers' spiritual cultivation and growth are part of the research endeavor" (p. xi). The book offers multiple and diverse ways to conceptualize and execute research through a spiritual research paradigm (SRP), and many of the chapters in this book offer substantive ideas, arguments, evidence, and applications of a SRP.

I appreciate the naming and distinguishing of a spiritual research paradigm because it is of critical importance to MSR, and I am making a different argument in this chapter. A SRP also means, at its core, that there are different paradigms from which a researcher can understand or make sense of the world. Naming and distinguishing different paradigms perpetuates separation (e.g., it is not aligned with a relational ontology) in these ways:

- It gives the researcher power to name and select one paradigm over the other;

- It leaves open the idea that the researcher is not in a co-emergent relationship with a chosen paradigm;

- It positions the researcher in the center of knowledge production;

- It assumes that reality is separated from our observation of it:

- It legitimizes/privileges paradigm (how to look at reality) over ontology (what is reality); and

- While it is a step forward to identify and start to legitimize different ways of knowing, it is limited to how researchers can know and does not address what there is to know (e.g., a relational reality).

A relational ontology, on the other hand, affirms that researchers literally cogenerate reality as we go about designing and implementing research projects. This 
ontological position suggests that the cognitive ideas of a researcher literally coemerge with the material conditions of the research. The researcher is embedded within the same relational web (Thayer-Bacon, 2017), the same quantum energetic field (Bohm, 1980), the same ceremonial space of reciprocity (Kimmerer, 2013) as the researched. The 'playing field' is leveled - the researcher is not like a coach directing the play of the game. The game is played through the researcher, not by the researcher.

Think about this for a moment. If the 'game' of research is played through the researcher, what might that mean to you? From an Indigenous ceremonial perspective, it means that there is no separation between knowledge and responsibility - all research is a moral and ethical act of reciprocity that recognizes the sovereignty and mindedness of all life. From a quantum perspective, it means that there exists an invisible, implicate order of unity between researcher and research that reflects continual emergence or becoming. From a Thayer-Bacon (2017) perspective, it means that ontology and spirituality are interchangeable and that all research can be considered manifestations of the sacred - if the researcher opens to the flow of what wants to emerge.

So, why should MSR researchers enact a relational ontology? The answer is perhaps controversial but it is clear: because through research we are given another opportunity to serve the source; the sacred; or in a different sense What Wants To Emerge from the implicate order (Bohm, 1980) or the consciousness of connectedness (Tsao \& Laszlo, 2019). In alignment with Lin et al (2016), this means the inner landscape of the researcher needs to be cultivated and nurtured; but perhaps different from these authors, the knowing and the research comes from an ontological Unity that is impossible to name or classify.

The next section offers some practical ideas for implementing research through enacting a relational ontology.

\section{How Might MSR Researchers Conduct Research Allow Research to Flow Through Them?}

The reframing of the question above signals the profound shift when enacting a relational ontology. The egoic researcher shifts into a way of being in resonance with the unseen field of energy and information that Indigenous wisdom and the quantum theory point to. From this field, the purpose, implementation, and impact of the research can emerge. This section describes how MSR researchers might think about and then not think about conducting research through enacting a relational ontology.

The purpose of MSR research studies is usually related to some management topic connected to spirituality or religion - topics often under-researched in mainstream management and organization science. This research is focused on human experiences involving deep interconnectedness, transcendence, growth, transformation, mystery, 
or joy. These types of experiences often tap into a sense of flow (Csikszentmihalyi, 2008), Qi (Tsao \& Laszlo, 2019), or what Gary Zukav (2014) calls authentic power: "the alignment of personality with the soul - and of multisensory perception: the expansion of human perception beyond the limitations of the five senses" (p. xxx). These deeply human/spiritual experiences are the topics of MSR research, which in the Newtonian perspective have been 'relegated' to non-scientific status.

Typically, we have been trained to craft a precise, well-defined, goal- and outcome-directed purpose statement for our research. The purpose is traditionally connected to a gap in knowledge, and the research intends to contribute towards filling that gap. Creswell (2016) argues that the purpose statement is the most important statement in a study, and that it should convey the essence of the project.

However, the genesis of the purpose is what is different when one enacts a relational ontology. Rather than beginning with a problem of practice to define the research problem, or anchoring a research problem in a gap in the literature, a researcher enacting a relational ontology will begin with mindfully looking inward/ outward to sense or intuit what wants to emerge from the field of becoming. The moments of clarity or knowing may be brief, intermittent, or rare, but the researcher knows when they happen. Much has been written on this more subtle and inward knowing in research, for example, in the discipline of transpersonal psychology (Anderson \& Braud, 2011; Braud \& Anderson, 1998) and Jungian perspectives on research (Romanyshyn, 2013). Tsao and Laszlo (2019) point to existing research that suggests that "consciousness might in fact exist outside the brain rather than be generated by it" (6).

The challenge is how expand this capacity for accessing, surrendering, or opening to this larger field of potential. The next section offers suggestions from the discipline of transpersonal psychology. I have found that this discipline has generated dissertations, textbooks, and scholarly articles on practical and implementable ways to connect the material with the subtle world through research. There is a paradox in this that is important to recognize: naming and identifying steps to access is needed for many of us who are learning and developing competencies for this work. At the same time, we risk missing the ineffable if we don't let go of our rational/cognitive brain. The key is to hold both/and lightly.

\section{Practices and Competencies for MSR Researchers}

This section describes three ways that MSR researchers can deepen their abilities to enact relational ontology in their research. First, I describe different ways to access non-rational ways of knowing, following suggestions by transpersonal research scholars Anderson, Braud and Clements (Anderson, 2011; Braud \& Anderson, 1998; Clements, 2011). Second, I argue for the importance of shadow work and synchronicities. 
And third, I recommend using the language of metaphor for communicating research; Romanyshyn (2013) calls this a poetics of research.

Accessing Non-Rational Ways of Knowing. According to researchers Anderson and Braud (2011), researchers can access moments of clarity through four portals of understanding - thinking, sensing, feeling, and intuition. However, the researcher needs to cultivate ease and expertise in all four ways of knowing. Anderson and Braud's book Transpersonal Research Methods for the Social Sciences: Honoring Human Experience offers well-tested tools and steps for researchers to take to develop their fullest capacity in these multiple ways of knowing. They have identified three categories: 1) accessing usually unconscious processes (tacit knowing, active imagination, automatic writing, etc); 2) accessing direct knowing (intuition, sympathetic resonance, presencing); and 3) empathic identification (accurate, not emotional, identification with the phenomenon of study; for example: researchers Feynman identified as an electron and McClintock identified as a corn fungus chromosome) (Anderson \& Braud, 2011, p. 250).

All three of these practices can facilitate our ability to have a direct/intuitive (Tsao \& Laszlo, 2019) experience of surrendering to the cosmic purpose of our MSR research. At the same time, there are many challenges direct/intuitive knowing brings to a scholar/researcher. For example, direct intuitive experiences can challenge beliefs in normal science with its subject/object split. Direct intuitive experiences can challenge the belief that the world is made out of discrete entities. And for people who have not had direct/intuitive experiences, it is difficult to 'believe' in these ways of knowing because there is no shared meaning for shared comprehension. These non-rational ways of sensing or intuiting/knowing the world seem to require a personal subjective experience of direct knowing.

Interestingly, research on visual perception may offer an explanation and opportunity/hope for enhancing a shared understanding. Research is starting to understand the disjuncture between 'knowing' in an intellectual, analytical sense and 'knowing' that is direct/intuitive. These findings may explain some of the reasons why not everyone has 'seen' or 'sensed' a relational or quantum reality. For example, research has suggested that one cannot have a 'rational' scientific view and a direct/intuitive view at the same time (Mayer, 2007):

The perceptions that characterize potentially anomalous experience [for example, a direct/in-
tuitive experience] appear to emerge from a state of mind that is, in the moment of perception,
radically incompatible with the state of mind in which perceptions characterizing rational
thought are possible . . . That's a murderous proposition for most of us trained in a Western
intellectual and scientific tradition ... . We're not accustomed to scientific investigation in
which the phenomena we're attempting to study are themselves exclusive of the state of mind
that lets us study them,"
(Mayer, 2007, p. 137)

This suggests that the state of mind associated with a relational ontology, including experiences with direct/intuitive knowing and other anomalous experiences (e.g., distance seeing), simply cannot be understood with the state of mind associated 
with Newtonian science. Ultimately, MSR researchers need to develop capacity to move between these two ways of experiencing the world to fully enact a relational ontology.

Doing Shadow Work. Romanyshyn (2013), also from the discipline of psychology as are Anderson, Braud, and Clements (Anderson, 2011; Braud \& Anderson, 1998; Clements, 2011), is a Jungian psychologist/philosopher and has a different focus on what the researcher needs to do and what skills or competencies to develop. I believe the contributions in his book The Wounded Researcher: Research with Soul in Mind is critical when considering research from a relational ontology for many reasons. For example, the Jungian perspective expands the inner field within which the researcher works to include psyche (the unconscious) and its connection to synchronicity. This connection is important for epistemological and rhetorical reasons. Readers are urged to review the full book to get a broader understanding of the many potential contributions to MSR research a Jungian view offers.

Jung wrote about the intersection of quantum physics and psychology and found that both disciplines had an epistemological problem related to "the indissoluble bond that exists between the object to be investigated and the human investigator" (Romanyshyn, 2013, p. 31). To Jung, synchronicity (e.g., meaningful coincidences without apparent causal connection) in human experience is similar to the "form that light takes" (32) in relation to a researcher in a physics lab. Just like the property of light depends on the researcher observing it, so too the form of the material world (e.g., meaningful coincidences) depend on the unconscious state (e.g., psyche) of the observer. To Jung, "something about the unconscious state links psyche to matter," (p. 32).

Taking this idea into account as a MSR researcher would mean that the unconscious could influence the research process, and consequently any research claims or findings. This has huge implications for the potential value (or lack of value) of research. I sense that inner work, shadow work, and practices of connectedness (Tsao \& Laszlo, 2019) would be critical elements of researcher preparation in order to be as clear a channel as possible for 'what wants to emerge' through the research process. Researchers would need to practice rigorous self-awareness and selfdevelopment strategies to prevent their research from becoming therapy (Anderson \& Braud, 2011). This type of concern is not only found here; in many references to autoethnographic research there is a concern for narcissistic or therapeutic elements to potentially influence the research process (Chang, 2008). Rather than discount the autoethnographic research process as inherently flawed and of no value, autoethnographers have been mindful and diligent, and have produced many contributions to science (see, for example, The Qualitative Report at https://nsuworks. nova.edu/do/search/?q=autoethnography\&start=0\&context=6227772\&facet $=$ ) There is no reason to believe that MSR researchers cannot do the same.

Writing Metaphorically. Jung also suggested that it is important for researchers to find language to communicate a neither/nor type of metaphoric sensibility rather than the usual both/and phrasing, and that both quantum physics and 
psychology have this challenge. “. . . Just as quantum physics has had to develop a language of probabilities, psychology needs to develop a language of potential and probable meanings, a language of approximations, a language that resists literalizing the visible and forgetting the invisible” (Jung, as cited in Romanyshyn, 2013, p. 35). Romanyshyn calls for researchers to consider metaphorical writing as a way to avoid objectification/freezing or reifying what is really always a potential - a fluid dynamic. Research findings or claims, if written in metaphor, would be "deliteralized, freed of their demand to be taken at face value, as the whole truth of the matter" (43).

I believe these three practices - accessing direct knowing, doing shadow work, and using metaphorical language (what Romanyshyn calls a 'poetics of research') are critical elements to consider in preparing for, implementing, and writing up MSR research through a relational ontology. Developing competency in accessing direct/intuitive awareness can aid MSR researchers to continually tap into the quantum/relational field while designing, conducting, and writing up research. This continued accessing can enhance the potential that the researcher is truly tapping into what wants to emerge, rather than merely filling a gap in the literature. Doing shadow work can provide a deep awareness of how the researcher's psyche may influence the research process. In addition, this work would seem to be another way for generating 'clear' and 'resonant' research findings free from ego. Finally, adopting a metaphorical view of the language of research could address the ineffable quality of human experiences relevant to quantum research.

\section{Summary and Invoking Intention}

The purpose of this chapter is to explore how MSR researchers might enact a relational ontology through research, and how this enactment might restore/repair the deep interconnection and interdependence between all life on the planet. The intention was to invite an expansion of the capacity of MSR researchers to conduct action-oriented, transformative, and emancipatory qualitative research.

Three different relational ontological views were presented, and specific ideas for enacting research from a relational ontological position were offered. The work of developing the inner capacities for this work involves non-linear, non-rational ways of knowing and being MSR researchers. From an IWOK perspective, the work is at once performative and normative, with the imperative to affirm and protect the sacredness of all life. The work is also healing and emancipatory, as illuminated through Johnston's (2017) Master's Thesis dedication: “To the colonized and to the colonizer. May we be free from the chains that keep us both from being what we are. Ayóóan..nishn.” (p. iii). 
May MSR researchers become fully what they are, through their research, and may this research catalyze transformation in body, mind, and spirit.

\section{References}

Ahmed, S. (2004). Declarations of whiteness: The non-performativity of anti-racism. Borderlands, 3 (2).

Allman, P. (2001). Critical Education Against Global Capitalism: Karl Marx and Critical Revolutionary Education. Bergin \& Garvey.

Anderson, R. (2011). Intuitive inquiry: The ways of the heart in human science research. In Transforming Self and Others Through Research: Transpersonal Research Methods and Skills for the Human Sciences and Humanities (pp. 15-70). State University of New York Press.

Anderson, R., \& Braud, W. (2011). Transforming Self and Others Through Research: Transpersonal Research Methods and Skills for the Human Sciences and Humanities. State University of New York Press.

Barad, K. (2003). Posthumanist performativity: Toward an understanding of how matter comes to matter. Signs: Journal of Women in Culture and Society, 28(3), 801-831. https://doi.org/ $10.1086 / 345321$

Bohm, D. (1980). Wholeness and the Implicate Order. Routledge.

Braidotti, R. (2018). Forword. In V. Bozalek, R. Braidotti, T. Shefer, \& M. Zembylas (Eds.), Socially Just Pedagogies: Posthumanist, Feminist and Materialist Perspectives in Higher Education. Bloomsbury Acadamic.

Braud, W., \& Anderson, R. (1998). Transpersonal Research Methods for the Social Sciences: Honoring Human Experience. Sage.

Chang, H. (2008). Autoethnography as Method. Routledge.

Clements, J. (2011). Organic inquiry: Research in partnership with spirit. In R. Anderson \& W. Braud (Eds.), Transforming Self and Others Through Research: Transpersonal Research Methods and Skills for the Human Sciences and Humanities (pp. 131-161). State University of New York Press.

Creswell, J. W. (2016). 30 Essential Skills for the Qualitative Researcher. SAGE.

Csikszentmihalyi, M. (2008). Flow: The Psychology of Optimal Experience. HarperCollins.

Cuomo, C. (2020). Knowledge and moral motivation: Getting closer. Tarka, 0, 62-67.

D'Arcangelis, C. L. (2018). Revelations of a white settler woman scholar-activist: The fraught promise of self-reflexivity. Cultural Studies $\leftrightarrow$ Critical Methodologies, 18(5), 339-353. https://doi.org/10.1177/1532708617750675

Gergen, K. J. (2009). Relational Being: Beyond Self and Community. Oxford University Press.

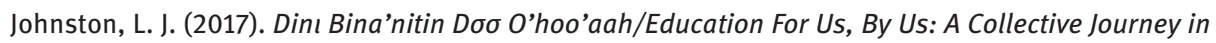
Dinı Education Liberation. https://digitalrepository.unm.edu/educ_llss_etds/85/

Kimmerer, R. W. (2013). Braiding Sweetgrass: Indigenous Wisdom, Scientific Knowledge and the Teachings of Plants. Milkweed Editions.

Kuhn, T. S. (1962). The Structure of Scientific Revolutions (4th ed.). University of Chicago Press.

Latour, B. (2005). Reassembling the Social: An Introduction to Actor-Network-Theory. Oxford University press.

Lin, J., Oxford, R. L., \& Culham, T. E. (2016). Toward a Spiritual Research Paradigm: Exploring New Ways of Knowing, Researching and Being. IAP. 
Loizzo, J. J. (2020). Why we all must be scholar-practitioners: Towards a global renaissance of the science and practice of human awakening. Tarka, 0, 68-81.

MacDonald, D. A. (2011). Studying spirituality scientifically: Reflections, considerations, recommendations. Journal of Management, Spirituality \& Religion, 8(3), 195-210. https://doi. org/10.1080/14766086.2011.599145

Maturana, H. R., \& Varela, F. J. (1980). Autopoiesis and Cognition: The Realization of the Living. Springer Science \& Business Media.

Mayer, E. L. (2007). Extraordinary Knowing: Science, Skepticism, and the Inexplicable Powers of the Human Mind. Bantam.

Romanyshyn, R. D. (2013). The Wounded Researcher: Research With Soul in Mind. Spring Journal Books.

Tackney, C. T., Chappell, S., Harris, D., Pavlovich, K., Egel, E., Major, R., Finney, M., \& Stoner, J. (2017). Management, spirituality, and religion (MSR) ways and means: A paper to encourage quality research. Journal of Management, Spirituality \& Religion, 14(3), 245-254. https://doi. org/10.1080/14766086.2017.1316764

Thayer-Bacon, B. J. (2017). Relational Ontologies. Peter Lang.

Tsao, F. C., \& Laszlo, C. (2019). Quantum Leadership: New Consciousness in Business. Stanford University Press.

Wilson, S. (2008). Research is Ceremony: Indigenous Research Methods. Fernwood Publishing. Zukav, G. (2014). The Seat of the Soul (25th ed.). Simon and Schuster. 